\title{
Estimating the Population at Risk with Soil Transmitted Helminthiasis and Annual Drug Requirements for Preventive Chemotherapy in Ogun State, Nigeria: A Bayesian Geostatistical Approach.
}

Hammed Mogaji ( $\square$ mogajihammed@gmail.com )

Federal University Oye-Ekiti

Olatunji Olugoke Johnson

Lancaster University Lancaster Medical School

Abass Bolaji Adigun

National Center for Remote Sensing, Jos

Oladunni Nimota Adekunle

Olabisi Onabanjo University

Samuel Olukayode Bankole

Federal University of Agriculture Abeokuta

Gabriel Adewunmi Dedeke

Federal University of Agriculture Abeokuta

Babatunde Saheed Bada

Federal University of Agriculture Abeokuta

Uwem Friday Ekpo

Federal University of Agriculture Abeokuta

\section{Research Article}

Keywords: Bayesian modelling, Nigeria, Ogun State, School-aged children, Adults, Preschoolers, Soiltransmitted helminthiasis

Posted Date: July 7th, 2021

DOl: https://doi.org/10.21203/rs.3.rs-645286/v1

License: (9) (1) This work is licensed under a Creative Commons Attribution 4.0 International License. Read Full License 
1 Estimating the population at risk with soil transmitted helminthiasis and annual drug requirements for preventive chemotherapy in Ogun State, Nigeria:

\section{A Bayesian geostatistical approach.}

Hammed Oladeji Mogaji ${ }^{1,2 *}$, Olatunji Olugoke Johnson³ ${ }^{3}$ Abass Bolaji Adigun ${ }^{4}$, Oladunni Nimota Adekunle ${ }^{5}$ Samuel Bankole ${ }^{2}$, Gabriel Adewunmi Dedeke ${ }^{2}$, Babatunde Saheed Bada ${ }^{6}$ and Uwem Friday Ekpo ${ }^{2}$

1 Department of Animal and Environmental Biology, Federal University, Oye-Ekiti, Ekiti, Nigeria, 2 Department of Pure and Applied Zoology, Federal University of Agriculture, Abeokuta, Nigeria 3 Centre for Health Informatics, Computing and Statistics, Lancaster Medical School, Lancaster University, Lancaster, United Kingdom 4 Department of Research and Application, National Centre for Remote Sensing, Jos, Nigeria 5 Department of Zoology and Environmental Biology, Olabisi Onabanjo University, Ago-Iwoye, Ogun, Nigeria 6 Department of Environmental Management and Toxicology, Federal University of Agriculture, Abeokuta, Nigeria

Corresponding author: *mogajihammed@gmail.com

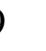

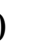

1


Abstract

30 Background: Soil transmitted helminth (STH) infections are among the most common human infections worldwide with over 1 billion people affected. Many estimates of STH infection are often based on school-aged children (SAC). This study produced predictive risk-maps of STH on a more finite scale, estimated the number of people infected, and the amount of drug required for preventive chemotherapy (PC) in Ogun state, Nigeria.

35

Methods: Georeferenced STH infection data obtained from a cross-sectional survey at 33 locations between July 2016 and November 2018, together with remotely-sensed environmental and socio-economic data were analyzed using Bayesian geostatistical modelling. Stepwise variable selection procedure was employed to select a parsimonious set of predictors to predict risk and spatial distribution of STH infections. The number of persons (preschoolers, SAC and adults) infected with STH were estimated, with the amount of tablets needed for preventive chemotherapy. the implementation units. The predictive maps revealed a spatial pattern of high risk in the central, western and on the border of Republic of Benin. The model identified soil $\mathrm{pH}$, soil moisture and elevation as the main predictors of infection for A. lumbricoides, Hookworms and T. trichiura respectively. About $50 \%(10 / 20)$ of the implementation units require biannual rounds of mass drug administration (MDA). Approximately, a total of 1.1 million persons were 
55 infected and require 7.8 million doses. However, a sub-total of 375,374 SAC were estimated to 56 be infected, requiring 2.7 million doses.

57

58 Conclusion: Our predictive risk maps and estimated PC needs provide useful information for 59 the elimination of STH, either for resource acquisition or identifying priority areas for delivery 60 of interventions in Ogun State, Nigeria.

61

62 Keywords: Bayesian modelling, Nigeria, Ogun State, School-aged children, Adults, 63 Preschoolers, Soil-transmitted helminthiasis

64 65 Word count: 347

66

67

68

69

70

71

72

73

74

75

76

77

78

79 


\section{Background}

Soil transmitted helminth (STH) infections are among the most common human infections worldwide and have been classified as neglected tropical diseases by the WHO [1,2]. Most of the world's STH infections are caused by four common parasitic helminths; Ascaris lumbricoides (roundworm), Trichuris trichiura (whipworm), Necator americanus and Ancylostoma duodenale (hookworms), whose life cycle are linked with the soil environment and a definitive human host $[2,3]$. STH infections are widely distributed in the tropical and subtropical regions, with the greatest numbers occurring in sub-Saharan Africa, the Americas, China and East Asia [1,3]. About 5 billion people are at risk, and 1.5 billion of the worlds' population are currently infected [1,3]. Infections are predominantly abundant in areas characterized with poverty, favorable climate and lack of access to basic infrastructural amenities such as potable water supply, sanitation and hygiene facilities [4-9].

Efforts targeted at controlling STH have been through preventive chemotherapy (PC), and involves large-scale administration of albendazole or mebendazole medicines with a major focus on school-aged children (SAC) in endemic communities [1,10]. The World Health Organization (WHO) recommends PC, either once a year (annually), when the baseline prevalence of infections is between 20 and $50 \%$, or twice a year (biannually) when the prevalence is above 50\% [10]. PC is expensive, costing donor agencies and developing economies billions of dollars [11]. For instance, since 2010, the World Health Organization (WHO) has coordinated the annual distribution of 600 million medicines for PC in endemic countries, with albendazole, donated by GlaxoSmithKline, and mebendazole, donated by Johnson \& Johnson [12].

In line with elimination goals, the WHO stipulates that endemic countries must consistently treat and protect at least $75 \%$ of its population that requires treatment. Globally, a total of 576 
108 million $(59.9 \%)$ of the estimated 1.1 billion children requiring albendazole or mebendazole

109 medicines were treated in 2018, and about $71.3 \%$ of the implementation units (IUs) achieved

110 the $75 \%$ effective coverage target for SAC $[12,13]$. However, the recently published 2020-

1112030 NTD road map, emphasized more specific targets by 2030 which includes (i) eliminating

$112 \mathrm{STH}$ as a public health problem ( $<2 \%$ proportion of moderate and heavy intensity infections) in

11396 countries; (ii) reducing by 50\% the number of tablets required during PC for STH and (iii)

114 increasing domestic financial support for PC for STH, with 25 countries deworming children

115 using domestic funds [12, 14-15].

116

117 These targets call for more refined commitments in the planning and delivery approaches for

118 large-scale administration of PC tablets to SAC, most especially in areas where prevalence

119 estimates are high [16-18]. It is therefore important to constantly delineate highly endemic

120 areas using parasitological surveys, and produce risk maps for unsampled areas using

121 geostatistical methods to support targeting and delivery of tablets for PC [19-21]. Approaches

122 combining parasitological surveys, geographical information systems (GIS), remote sensing

123 (RS), spatial and geostatistical analysis have been explored extensively to model and predict

124 the risk of helminth infections on a national scale in China [20], Cote'd voire [21], Cambodia

125 [22], South America [23] and Nigeria [24]. Yet, there is paucity of studies investigating risk

126 factors explaining spatial distribution of STH at a more finite scale such as the implementation

127 units (IUs). Model based geostatistical approaches are useful in understanding the variations

128 that exist within IUs, which are necessary for targeting intervention in hotspot area with high

129 prevalence.

131 Nigeria is endemic for all the four common STH infections, and leading in terms of burden,

132 and the number of people infected in sub-Saharan Africa [25,26]. Information on the spatial

133 distribution and risk of STH infections is needed to facilitate targeting of control efforts in the 
134 context of resource scarcity. The few published studies in the country, have used secondary

135 survey data to produce county-level risk maps [24,27-28] and annual drug requirements [24].

136 Since implementation of PC occur in a more finite scale at IUs (referred to as local government

137 areas (LGAs) in Nigeria), we hypothesize that risk maps made at these levels using real-time

138 parasitological data will offer more robust insight into disease distribution and risk factors

139 associated with such distributions. In addition, data generated at such IUs would be useful to

140 estimate number of people at risk or infected with STH, rounds of MDA and the drug 141 requirements for PC.

142

143 We therefore present findings from a geostatistical analysis of soil-transmitted helminth

144 infection data that were obtained from a state-wide community-based survey in Ogun State,

145 Nigeria. The aims of this study were (i) to map and predict the spatial distribution of soil146 transmitted helminth infections at $2 \mathrm{~km}$ spatial scale using a Bayesian geostatistical approach;

147 (ii) identify the most important climatic, environmental and socioeconomic determinants of 148 soil-transmitted helminth infections (iii) calculate the number of persons infected and; (iv)

149 estimate the annual drug requirements for preventive chemotherapy according to guidelines put 150 forward by the World Health Organization (WHO). 


\section{Study area, design and population}

This study was conducted in Ogun State, Nigeria (Figure 1). Details of the study area, design and population surveyed have been described elsewhere [19]. In brief, the study was carried out between July 2016 and November 2018 spanning across both wet and dry season. We designed

171 a cross-sectional survey, and employed a systematic grid sampling method in the selection of

172 communities to ensure an unbiased representation across the state. A total of 1,499 children and 173 adults, from 33 spatially selected communities participated in the study [19]. In each 174 community, all households and their occupants were considered eligible for participation and 175 invited to participate in the study.

\section{STH Infection data}

The field and laboratory procedures have been previously described in [19]. In brief, stool container was distributed to consenting household members in advance. Participants' unique identifiers were marked on the containers and detailed instructions of how to collect a fresh morning stool sample were given. Stool samples were processed in a designated area provided

182 by the community leader. Duplicate sediment slides were prepared from $1 \mathrm{~g}$ of each stool using SAF-Ether concentration method $[19,29]$. The slides were examined under a light microscope by experienced laboratory technicians 2 hours post sample collection. Infection was defined as the presence of at least one helminth egg on one of the two slides. The parasites' eggs were counted for each species, and number of eggs per species and per stool examined was recorded

187 for each participant [19]. 
193 Nine environmental variables (elevation, enhanced vegetation index (EVI), normalized

194 difference vegetation index (NDVI), land surface temperature for day (LSTD), land surface

195 temperature for night (LSTN), rainfall, population, soil $\mathrm{pH}$, and soil moisture; three socio-

196 economic variables (night light emission (NLE), improved access to sanitation facilities and

197 improved access to drinking water facilities) were used in the analysis. NLE was used as a

198 proxy for urbanization and economic growth. NLE was used as a proxy for urbanisation and

199 economic growth. These variables were chosen because they are either directly associated with

200 prevalence of STH infections or they serve as proxy for other factors that are known to 201 influence STH transmission [30]. All environmental and socio-economic data were obtained 202 from open-access remote sensing data sources between 2016 and 2018 (Table 1). We 203 resampled all the covariates to a spatial resolution of $2 \mathrm{~km}$ by $2 \mathrm{~km}$ using bilinear interpolation 204 for continuous surface which is required to produce the spatial prediction of prevalence at 205 every location in Ogun state.

\section{Population data}

208 Population data of Nigeria at 100m spatial resolution was obtained from World Pop [31] 209 population database. The total population count of people in Ogun state in 2017 was 5,103,988 out of 197,259,740 people in Nigeria. The number of school-aged children in Ogun state in 2017 was computed to be $1,913,868$, which represents $37.5 \%$ of the total population of all 212 persons. 

explored to model soil transmitted helminthiasis risk in Ogun State, Nigeria

\begin{tabular}{|c|c|c|c|c|}
\hline Data type & Source & $\begin{array}{l}\text { Temporal } \\
\text { resolution }\end{array}$ & $\begin{array}{l}\text { Temporal } \\
\text { coverage }\end{array}$ & $\begin{array}{l}\text { Spatial } \\
\text { resolution (m) }\end{array}$ \\
\hline \multicolumn{5}{|l|}{ Environmental covariates } \\
\hline Elevation & WorldPop [31] & & & $100 \mathrm{~m}$ \\
\hline Enhanced vegetation index (EVI) & MODIS/Terra [32] & 16 days & 2016-2018 & $250 \mathrm{~m}$ \\
\hline $\begin{array}{l}\text { Normalized difference vegetation index } \\
\qquad(\mathrm{NDVI})\end{array}$ & MODIS/Terra [32] & 16 days & 2016-2018 & $250 \mathrm{~m}$ \\
\hline Rainfall & MODIS/Terra [32] & 10 days & 2016-2018 & $250 \mathrm{~m}$ \\
\hline Soil pH & SoilGrids250m [33] & & 2016-2018 & $250 \mathrm{~m}$ \\
\hline Soil Moisture & C3S [34] & & 2016-2018 & $1000 \mathrm{~m}$ \\
\hline Population density & WorldPop [31] & & 2017 & $100 \mathrm{~m}$ \\
\hline Land surface temperature (Day) & MODIS/Terra [32] & 8 days & 2016-2018 & $1000 \mathrm{~m}$ \\
\hline Land surface temperature (Night) & MODIS/Terra [32] & 8days & 2016-2018 & $1000 \mathrm{~m}$ \\
\hline \multicolumn{5}{|l|}{ Socio-economic covariates } \\
\hline Night light emission & WorldPop [31] & & 2017 & $100 \mathrm{~m}$ \\
\hline Improved access to sanitation facilities & LBD [35] & & 2017 & $5000 \mathrm{~m}$ \\
\hline Improved access to drinking water facilities & LBD [35] & & 2017 & $5000 \mathrm{~m}$ \\
\hline
\end{tabular}

222 Variable selection procedures for the geostatistical model

223 To select the best set of covariates for the geostatistical model, we first examined the covariates

224 for correlation using Pearson's rank correlation index. Pairs of covariates with high correlation

225 values (Pearson correlation > 0.7) were identified and only one of the correlated variables was

226 included in the modelling process. Then we used both forward and backward stepwise

227 selection to select a parsimonious set of covariates required for the prediction of STH among

228 all the candidate set of covariates. This is achieved by fitting a non-spatial generalised linear

229 model relating the prevalence of each STH species with the covariates. The final set of 
covariates result in a model with the lowest Akaike information criterion (AIC) and a further

231 inclusion of any of the covariates does not improve the performance of the model.

\section{Geostatistical modelling}

234 The prevalence survey data available for this analysis are, at any geographical location $\mathrm{x}$, the 235 number of individuals tested, $m$ and the number of people tested positive for each of the STH 236 species, $y_{k}$, where $y_{1}$ is the number of people that tested positive for Ascaris, $y_{2}$ for 237 Hookworm, and $y_{3}$ for Trichuris. The sampling distribution of $y_{k}$ is binomial with number of 238 trials $\mathrm{m}$ and probability of positive outcome $P_{k}(x)$, the prevalence at $\mathrm{x}$. The variation of $239 P(x)$ was modelled using a combination of socio-economic and environmental covariate effects $240 \mathrm{~d}(\mathrm{x})$; unexplained residual spatial variation, $\mathrm{S}(\mathrm{x})$. Therefore, we developed a binomial logistic 241 geospatial model given as

$$
\log \left\{\frac{P(x)}{1-P(x)}\right\}=d^{\prime}(x) \beta+S(x)
$$

$S(x)$ is modelled as a zero-mean discretely indexed Gaussian Markov Random Field (GMRF)

244 defined on the triangulation of the domain of interest, such that the correlation between any two 245 locations $x_{i}$ and $x_{j}$ is modelled using Matérn correlation function. $\mathrm{S}(\mathrm{x})$ serves two purposes in 246 the model; 1) it helps to capture the geographical variation; and 2) it helps to predict prevalence 247 at unobserved locations. The Matérn covariance function is given as

$$
\operatorname{Cov}\left(S\left(x_{i}\right), S\left(x_{j}\right)\right)=\frac{\sigma^{2}}{2^{v-1} \Gamma(v)}(\kappa u)^{v} K_{v}(\kappa u),
$$

where $d=\left\|x_{i}-x_{j}\right\|, \kappa$ is a scaling parameter, $K_{v}$ is the modified Bessel function of second kind and order $v>0$ and $\Gamma($.$) is the Gamma-function, \sigma^{2}$ is the variance, and the spatial range $\rho=\sqrt{8} / \kappa$, the distance at which the spatial correlation is becomes negligible $(<0.1)$. The model was fitted using the Integrated Nested Laplace Approximation (INLA) [36,37] and the Stochastic Partial Differential Equation (SPDE) [38] approaches. INLA allows us to perform a fast Bayesian inference. Because no prior information was available, an independent 
vague zero-mean Gaussian prior distribution was assigned to the fixed and random effects

256 parameters. Posterior distributions were obtained for all the parameters and were summarised 257 to obtain the mean and $95 \%$ credible interval (CI). Prediction of the prevalence of each of the 258 STH species were provided at $2 \mathrm{~km}$ spatial resolution throughout the study area. We then 259 estimate the prevalence of any STH prevalence by assuming that each species is independent 260 [38]. The predicted prevalence was represented as the posterior mean.

\section{Model Validation}

We validated our geostatistical model by assessing the predictive performance of the model using the 5-folds cross-validation. All survey data were randomly splitted into 5 groups. We hold-out each unique group then fit the model on the remaining groups and evaluate the predictive performance of the model on the hold-out group. The withheld data was matched with the predictions to summarize the performance of the model using the correlation, bias, root mean square error (RMSE) and the coverage probability.

\section{Estimating the amount of the anthelmintic treatment required}

271 We estimated the amount of anthelmintic treatment (albendazole or mebendazole) needed to treat the population annually at the local government areas in Ogun state. According to the WHO STH treatment decision tree [40], prevalence of STH should be examined after 5-6 rounds of annual or biannual PC. Subsequent chemotherapy campaigns after this evaluation should continue according to a set of endemicity classes defined by the following prevalence thresholds; suspend PC if prevalence is <2\%; biennial PC if prevalence is between 2 and $10 \%$; annual PC if prevalence is between 10 and 20\%; biannual PC if prevalence is between $20 \%$ and $50 \%$; triannual PC is prevalence is greater than 50\% [40]. Hence, we computed the total number of anthelmintic drugs by classifying each pixel according to the treatment decision, 
281 the total population of that pixel. Hence, we aggregate across the pixels the number of 282 anthelmintic drugs over the local government areas. Also, we estimated the number of 283 anthelmintic drugs required to treat school-aged children (SAC) by multiplying the number of 284 MDA rounds per pixel by the population of SAC per pixel. Then we constructed the local 285 government level estimate by aggregating across the pixels.

\section{Estimating the number of people infected with STH}

288 To estimate the number of people infected with STH parasites, we multiplied the prevalence at each pixel by the total population at that pixel. Also, to estimate the number of SAC infected with STH parasite, we multiplied the prevalence at each pixel by the population of SAC at that pixel. Hence, to construct the local government level estimate, we aggregate the values across the pixels. The $95 \%$ confidence interval of the estimate was constructed by using the prevalence values at the $2.5 \%$ and $97.5 \%$ quantiles. 


\section{Data Summaries}

323 A total of 1,027 infection data was included in this survey. The demographic characteristics of 324 the study population have been described elsewhere [19]. However, Table 2 summarizes the 325 soil-transmitted helminths species-specific prevalence among the examined participants. In 326 short, an overall prevalence of $17.2 \%$ (95 \% CI: 14.9, 19.5) was recorded for any STH 327 infection. Ascaris lumbricoides infections was the most predominant, with an overall 328 prevalence of $13.6 \%$ (95\% CI: 11.5, 15.7), while Hookworm and Trichuris trichiura had 329 overall prevalence of $4.6 \%$ (95 \% CI: 3.3, 5.9) and $1.7 \%$ (95\% CI: 0.9, 2.4), respectively. The 330 geographical distribution of the observed prevalence for each soil-transmitted helminth species 331 has been described elsewhere [19]. 
Table 2: Soil-transmitted helminth species-specific observed prevalence across the 20 LGAs in Ogun State, Nigeria, Mid 2016-Early, 2018

\begin{tabular}{|c|c|c|c|c|c|c|c|c|c|}
\hline \multirow[b]{2}{*}{ LGA } & \multirow[b]{2}{*}{$\mathrm{N}$} & \multicolumn{2}{|c|}{ Ascaris lumbricoides } & \multicolumn{2}{|c|}{ Hookworms } & \multicolumn{2}{|c|}{ Trichuris trichiura } & \multicolumn{2}{|c|}{ Any STH } \\
\hline & & $\mathrm{n}, \%$ & $95 \% \mathrm{CI}$ & $\mathrm{n}, \%$ & $95 \% \mathrm{CI}$ & $\mathrm{n}, \%$ & $95 \% \mathrm{CI}$ & $\mathrm{n}, \%$ & $95 \% \mathrm{CI}$ \\
\hline Abeokuta South & 14 & $5,35.7$ & $10.6,60.8$ & $1,7.1$ & $0,20.6$ & 0,0 & 0,0 & $6,42.9$ & $16.9,68.6$ \\
\hline Abeokuta North & 40 & $7,17.5$ & $5.7,29.3$ & $1,2.5$ & $0,7.3$ & 0,0 & 0,0 & 8,20 & $7.6,32.4$ \\
\hline Ado-Odo Ota & 56 & $6,10.7$ & $2.6,18.8$ & $2,3.6$ & $0,8.4$ & $4,7.1$ & $0.4,13.9$ & $8,14.3$ & $5.1,23.5$ \\
\hline Ewekoro & 46 & $3,6.5$ & $0,13.7$ & 0,0 & 0,0 & 0,0 & 0,0 & $3,6.5$ & $0,13.7$ \\
\hline Ifo & 19 & $5,26.3$ & $6.5,46.1$ & $3,15.8$ & $0,32.3$ & 0,0 & 0,0 & $7,36.8$ & $15.2,58.5$ \\
\hline Ijebu East & 38 & $6,15.8$ & $4.2,27.4$ & 0,0 & 0 & $1,2.6$ & $0,7.7$ & $6,15.8$ & $4.2,27.4$ \\
\hline Ijebu Ode & 25 & 0,0 & 0,0 & 0,0 & 0,0 & 0,0 & 0,0 & 0,0 & 0,0 \\
\hline Ijebu North & 48 & $6,12.5$ & $3.1,21.9$ & $1,2.1$ & $0,6.1$ & 0,0 & 0,0 & $6,12.5$ & $3.1,21.9$ \\
\hline Ijebu North-East & 26 & $4,15.4$ & $1.5,29.3$ & 0,0 & 0,0 & 0,0 & 0,0 & $4,15.4$ & $1.5,29.3$ \\
\hline Ikenne & 36 & $11,30.6$ & $15.5,45.6$ & 0,0 & 0,0 & 0,0 & 0,0 & $11,30.6$ & $15.5,45.6$ \\
\hline Imeko-Afon & 86 & $4,4.7$ & $0.2,9.1$ & $2,2.3$ & $0,5.5$ & 0,0 & 0,0 & $5,5.8$ & $0.9,10.8$ \\
\hline Ipokia & 13 & $4,30.8$ & $5.7,55.9$ & $2,15.4$ & 0,35 & $3,23.1$ & $0.2,46$ & $5,38.5$ & $12,64.9$ \\
\hline Obafemi Owode & 54 & $15,27.8$ & $15.8,39.7$ & $9,16.7$ & $6.7,26.6$ & $4,7.4$ & $0.4,14.4$ & $22,40.7$ & $27.6,53.8$ \\
\hline Odeda & 71 & $4,5.6$ & $0.3,11$ & $6,8.5$ & $2,14.9$ & 0,0 & 0,0 & $8,11.3$ & $3.9,18.6$ \\
\hline Odogbolu & 54 & $6,11.1$ & $2.7,19.5$ & $1,1.9$ & $0,5.4$ & 0,0 & 0,0 & 7,13 & $4,21.9$ \\
\hline Ogun waterside & 85 & $16,18.8$ & $10.5,27.1$ & $5,5.9$ & $0.9,10.9$ & $1,1.2$ & $0,3.5$ & $20,23.5$ & $14.5,32.5$ \\
\hline Remo North & 15 & $4,26.7$ & $4.3,49$ & $2,13.3$ & $0,30.5$ & 0,0 & 0,0 & 6,40 & $15.2,64.8$ \\
\hline Shagamu & 128 & 9,7 & $2.6,11.5$ & $3,2.3$ & 0,5 & 0,0 & 0,0 & $10,7.8$ & $3.2,12.5$ \\
\hline Yewa North & 114 & $3,2.6$ & $0,5.6$ & $2,1.8$ & $0,4.2$ & $1,0.9$ & $0,2.6$ & $6,5.3$ & $1.2,9.4$ \\
\hline \multirow[t]{2}{*}{ Yewa South } & 59 & $22,37.3$ & $24.9,49.6$ & $7,11.9$ & $3.6,20.1$ & $3,5.1$ & $0,10.7$ & $29,49.2$ & $36.4,61.9$ \\
\hline & 1027 & $140,13.6$ & $11.5,15.7$ & $47,4.6$ & $3.3,5.9$ & $17,1.7$ & $0.9,2.4$ & $177,17.2$ & $14.9,19.5$ \\
\hline
\end{tabular}

$\mathrm{N}=$ number of samples examined; $\mathrm{n}=$ number of positives; $\mathrm{CI}=$ Confidence intervals 


\section{Geostatistical variable selection, model parameter estimates and model validation}

335 Following the variable selection, Soil pH, soil moisture and elevation were selected for Ascaris, 336 Hookworms, and Trichuris infections respectively (Table 3). The selected covariates were used

337 to build predictive risk models specific to each of the three soil transmitted helminth species. A 338 negative association exist between Ascaris lumbricoides infection and soil pH (odds ratio $(\mathrm{OR})=$ $339-0.05 ; 95 \%$ Bayesian credible interval (BCI): $-0.071,-0.029)$. Residual spatial correlation was 340 estimated to be $12.813 \mathrm{~km}(95 \%$ BCI: 5.199, $26.760 \mathrm{~km})$. Similarly, a negative association was

341 observed between Hookworms and soil moisture (odds ratio $(\mathrm{OR})=-0.027$; $95 \%$ Bayesian 342 credible interval (BCI): $-0.042,-0.015)$. Residual spatial correlation was estimated to be 17.823

343 km (95 \% BCI: 4.834, 50.090 km). For Trichuris trichiura, infection risk was also negatively 344 associated with elevation (odds ratio $(\mathrm{OR})=-0.027 ; 95 \%$ Bayesian credible interval (BCI): 345 0.042, -0.015). Residual spatial correlation was estimated to be $5.427 \mathrm{~km}$ (95\% BCI: 2.789, $34617.190 \mathrm{~km})$. The predictive performance of the model based on a 5-folds cross-validation 347 showed that the in-sample observed data and the predictions has a coefficient correlation of 0.83 ; 348 a RMSE of 0.05 ; and a bias of -0.01 ; and coverage probability of 0.86 , respectively. 
359 Table 3: Posterior estimates (median; 95\% Bayesian credible interval) of the final 360 geostatistical models for soil-transmitted helminth infections in Ogun State, Nigeria in $361 \quad \mathbf{2 0 1 6 - 2 0 1 8}$

362

\begin{tabular}{lll}
\hline Species & Predictors & OR $(\mathbf{9 5} \% \mathbf{B C I})$ \\
\hline Ascaris lumbricoides & Intercept & $-0.051(-1.188,1.014)$ \\
\hline & Soil pH & $-0.051(-0.074,-0.029)$ \\
\hline & Spatial variance & $0.861(0.573,1.240)$ \\
\hline & Spatial scale $(\mathrm{km})$ & $12.813(5.199,26.760)$ \\
\hline Hookworm & & \\
\hline & Intercept & $-1.323(-2.423,-0.104)$ \\
\hline & Soil moisture & $-0.027(-0.042,-0.015)$ \\
\hline Spatial variance & $0.918(0.485,1.540)$ \\
\hline & Spatial scale $(\mathrm{km})$ & $17.823(4.834,50.090)$ \\
\hline & & \\
\hline & Intercept & $-3.028(-3.974,-2.164)$ \\
\hline & Elevation & $-0.027(-0.042,-0.015)$ \\
\hline & Spatial variance & $1.158(0.504,2.290)$ \\
\hline & Spatial scale $(\mathrm{km})$ & $5.427(2.789,17.190)$ \\
\hline
\end{tabular}




\section{Predictive risk maps of soil-transmitted helminth infections}

Overall predicted mean prevalence of STH infections in Ogun State is $19.2 \%$ (95 \% CI: 1.82, 58.9) and ranges from $7.0 \%$ to $38 \%$ across the IUs. However, by species, predicted mean prevalence for Ascaris lumbricoides was $12.4 \%$ (95\% CI: 0.98, 44.9), ranging from $5.0 \%$ to $23.8 \%$ across the IUs. For hookworms, the predicted mean prevalence was $6.2 \%$ (95\% CI: $0.73,22.5$ ), and ranges between $2.0 \%$ to $14.5 \%$ across the IUs. The predicted mean prevalence of $1.9 \%(95 \%$ CI: $0.13,8.84)$ was estimated for Trichuris trichiura, with a range between $0.1 \%$ and $5.7 \%$ across the IUs (Table 4). Figures 2, 3, 4 and 5 present the overall and species-specific predictive risk maps of soil-transmitted helminth infections. Predictive risk map for overall STH infection shows a high prevalence $(>20 \%)$ for LGAs in the central and western part of the state. Pockets of very high prevalence $(>40 \%)$ were also predicted for the LGAs around the boundary regions in the south-western part of the state. However, predicted prevalence were predominantly between $12-15 \%$ in the eastern part of the state. For Ascaris lumbricoides, high prevalence (>20\%) was predicted in the central and western part of Ogun State, with hotspots in the LGAs located close the border regions in the south-western part of the country. Moderate to high prevalence (5-20\%) were also predicted in these regions. However, low predicted prevalence (5$10 \%$ ) were observed in the eastern part of the country, with a sparse predicted prevalence within $10-12 \%$ around the border regions (Figure 2). For hookworms, the predicted risk map shows that most regions have prevalence below 20\%, except some pocket areas in Ipokia LGA, around the boundary lines. Predicted prevalence were predominantly between $5-10 \%$ in the central and western part of the state. However, predicted prevalence were lower $(2-5 \%)$ in the eastern regions (Figure 3). For Trichuris trichiura infections, most of the LGAs in the northern part of the state had predicted prevalence value between $0-1 \%$. Similarly, in the southern region, predicted prevalence were predominantly between 5-10\% (Figure 4). 


\begin{tabular}{|c|c|c|c|c|c|c|c|c|}
\hline \multirow[b]{2}{*}{ LGA } & \multicolumn{2}{|c|}{ Ascaris lumbricoides } & \multicolumn{2}{|c|}{ Hookworms } & \multicolumn{2}{|c|}{ Trichuris trichiura } & \multicolumn{2}{|c|}{ Any STH } \\
\hline & $\begin{array}{l}\text { Mean Prevalence } \\
(\%)\end{array}$ & $95 \% \mathrm{CI}$ & $\begin{array}{l}\text { Mean } \\
\text { Prevalence }(\%)\end{array}$ & $95 \% \mathrm{CI}$ & $\begin{array}{l}\text { Mean Prevalence } \\
(\%)\end{array}$ & $95 \% \mathrm{CI}$ & $\begin{array}{l}\text { Mean Prevalence } \\
(\%)\end{array}$ & $95 \% \mathrm{CI}$ \\
\hline Abeokuta South & 18.5 & $2.5,54.2$ & 9.6 & $2.2,25.7$ & 1.6 & $0.2,5.5$ & 27.5 & $4.8,67.8$ \\
\hline Abeokuta North & 15.1 & $1.3,51.6$ & 7.7 & $0.9,26.7$ & 1.1 & $0.1,4.5$ & 22.4 & $2.3,65.9$ \\
\hline Ado-Odo Ota & 12.4 & $0.7,49.6$ & 6.2 & $0.5,26$ & 3.1 & $0.3,14.5$ & 20.3 & $1.5,67.4$ \\
\hline Ewekoro & 15.3 & $1.2,52.5$ & 8.1 & $0.7,30.3$ & 1.4 & $0.1,6.5$ & 23.1 & $2,67.3$ \\
\hline Ifo & 17.5 & $1.7,56.3$ & 9.3 & $1.2,31$ & 2.3 & $0.2,9.5$ & 26.8 & $3.1,72.5$ \\
\hline Ijebu East & 11.3 & $0.9,41.7$ & 5.3 & $0.6,18.6$ & 1.8 & $0.1,7.4$ & 17.5 & $1.6,55.4$ \\
\hline Ijebu Ode & 11.2 & $0.6,47.1$ & 5.4 & $0.5,23.4$ & 3.1 & $0.1,16.3$ & 18.7 & $1.2,65$ \\
\hline Ijebu North & 6.7 & $0.5,26.9$ & 2.7 & $0.4,8.5$ & 0.7 & $0.1,2.4$ & 9.8 & $1,34.6$ \\
\hline Ijebu North-East & 8.7 & $0.4,37.8$ & 3.8 & $0.3,16$ & 2 & $0.1,8.8$ & 13.9 & $0.9,51.8$ \\
\hline Ikenne & 8.5 & $0.6,34.5$ & 3.7 & $0.5,13.7$ & 0.8 & $0.1,3.4$ & 12.6 & $1.1,44.7$ \\
\hline Imeko-Afon & 5 & $0.3,22.2$ & 2 & $0.2,7.2$ & 1 & $0.1,4.3$ & 7.7 & $0.5,30$ \\
\hline Ipokia & 10.5 & $0.9,38.2$ & 4.7 & $0.8,14.7$ & 0.9 & $0.1,3.3$ & 15.4 & $1.7,48.8$ \\
\hline Obafemi-owode & 14.6 & 1,53 & 7.7 & $0.6,30.7$ & 0.1 & $0,0.7$ & 21.1 & $1.6,66.4$ \\
\hline Odeda & 23.8 & $2.1,71.2$ & 14.5 & $1.5,51$ & 5.1 & $0.3,25$ & 38 & $3.9,88.1$ \\
\hline Odogbolu & 14.9 & $1.3,51.3$ & 7.5 & $1,25.6$ & 2.5 & $0.2,10.8$ & 23.2 & $2.4,67.7$ \\
\hline Ogun waterside & 15 & $1.1,53.7$ & 7.8 & $0.7,30$ & 0.4 & $0,1.9$ & 21.9 & $1.8,67.3$ \\
\hline Remo North & 6.3 & $0.4,27.6$ & 2.5 & $0.3,9.5$ & 2 & $0.1,8.6$ & 10.5 & $0.8,39.3$ \\
\hline Shagamu & 9.2 & $0.4,43.3$ & 4.4 & $0.3,21.7$ & 5.7 & $0.3,28.8$ & 18.1 & $1,65.3$ \\
\hline Yewa North & 14.2 & $1.2,49.7$ & 7 & $1,23.6$ & 0.7 & $0,3.3$ & 20.8 & $2.2,62.6$ \\
\hline \multirow[t]{2}{*}{ Yewa South } & 8.5 & $0.5,36.5$ & 3.8 & $0.4,15.8$ & 2.4 & $0.1,11.3$ & 14 & $1,50.5$ \\
\hline & 12.36 & $0.98,44.9$ & 6.16 & $0.73,22.5$ & 1.94 & $0.13,8.8$ & 19.2 & $1.82,58.9$ \\
\hline
\end{tabular}


398 Figure 2: Map showing the predicted risk of Any soil transmitted helminth infections in 399 Ogun State

$400 \quad$ Figure 3: Map showing the predicted risk of Ascaris lumbricoides infections in Ogun State

$401 \quad$ Figure 4: Map showing the predicted risk of Hookworm infections in Ogun State

402 Figure 5: Map showing the predicted risk of Trichuris trichiura infections in Ogun State

404 Estimates of number of people infected and annual drug requirements

Table 5 shows the number of infected individuals, estimated rounds of MDA and drug 408 requirements for combined treatment of entire population and school-aged population across the 409 IUs in the State. Half $(50 \%)$ of the IUs in the State requires biannual rounds of MDA, while $41040 \%(8 / 20)$ and $10 \%(2 / 20)$ requires annual and biennial MDA rounds respectively. For the 411 entire population, comprising of preschool-aged children, school-aged children and adults, a total 412 of 1,099,461 persons are estimated to be infected, requiring 7,866,374 drugs. By IUs, about 10 413 LGAs has over 50,000 infected persons each, requiring more than 300,000 albendazole or 414 mebendazole tablets. Ado Odo-Ota LGA has the highest number of infected population $(168,591$

415 persons) and requires 1,204,423 albendazole or mebendazole tablets. The least number of 416 infected population (9,103 persons) were estimated for Ijebu North-east, requiring 64,181 tablets.

418 However, for school-aged population, a total of 375,374 were infected, requiring 2,685,618 419 drugs for preventive chemotherapy. Ten LGAs in the central and western part of the state had 
420 over 10,000 infected school-aged children, and requires over 100,000 albendazole or 421 mebendazole tablets each, for mass administration campaigns. The highest number of infected 422 school-aged children $(56,556)$ were estimated for Ado-Odo Ota LGA, requiring a total of 423404,123 albendazole or mebendazole tablets. The least number of infected school-aged 424 population $(3,118)$ were estimated for Ijebu North-east, requiring 21980 tablets. 
Table 5: Estimates of number of people infected and annual drug requirements in Ogun State, Nigeria

\begin{tabular}{|c|c|c|c|c|c|}
\hline \multirow[b]{2}{*}{ LGAs } & \multirow[b]{2}{*}{$\begin{array}{l}\text { Rounds of } \\
\text { MDA }\end{array}$} & \multicolumn{2}{|c|}{ Total population* } & \multicolumn{2}{|c|}{ School-aged population } \\
\hline & & $\begin{array}{l}\text { Number Infected } \\
(95 \% \text { CI })\end{array}$ & $\begin{array}{l}\text { Drug required } \\
(95 \% \mathrm{CI})\end{array}$ & $\begin{array}{l}\text { Number Infected } \\
(95 \% \text { CI })\end{array}$ & $\begin{array}{l}\text { Drug required } \\
(95 \% \mathrm{CI})\end{array}$ \\
\hline Abeokuta South & Biannual & $96555(16734,238100)$ & $702821(175706,1054233)$ & $32531(5639,80218)$ & $236796(59200,355195)$ \\
\hline AbeokutaNorth & Biannual & $78023(8019,228140)$ & $626482(119234,1027760)$ & $26304(2703,76918)$ & $211211(40178,346516)$ \\
\hline AdoOdo/Ota & Biannual & $168591(13254,559035)$ & $1204423(57743,2446759)$ & $56556(4437,187567)$ & $404123(19332,821452)$ \\
\hline Ewekoro & Annual & $16261(1541,51124)$ & $112703(7651,251037)$ & $5295(502,16645)$ & $36703(2500,81721)$ \\
\hline Ifo & Annual & $144387(9163,503643)$ & $962756(56218,2259466)$ & $46987(2986,163857)$ & $313367(18346,735361)$ \\
\hline Ijebu North-East & Biennial & $9103(952,31813)$ & $64181(0,181466)$ & $3118(326,10895)$ & $21980(0,62147)$ \\
\hline IjebuEast & Annual & $23919(1575,88930)$ & $170024(2125,433783)$ & $8142(534,30285)$ & $57833(719,147608)$ \\
\hline IjebuNorth & Annual & $53164(4684,188646)$ & $404098(463,955878)$ & $18392(1620,65264)$ & $139790(160,330666)$ \\
\hline IjebuOde & Biennial & $17256(1108,67015)$ & $129554(0,399428)$ & $5735(368,22273)$ & $43047(0,132749)$ \\
\hline Ikenne & Annual & $25255(3005,79001)$ & $158432(22498,401004)$ & $9383(1117,29343)$ & $58859(8399,148883)$ \\
\hline Imeko-Afon & Biannual & $25379(1872,79777)$ & $205578(5469,349568)$ & $9543(704,29998)$ & $77292(2059,131463)$ \\
\hline Ipokia & Biannual & $79081(8309,184435)$ & $438345(86859,630572)$ & $28374(2983,66162)$ & $157248(31170,226190)$ \\
\hline Obafemi-Owode & Biannual & $73179(7628,213975)$ & $539667(77337,949675)$ & $24032(2505,70270)$ & $177229(25396,311887)$ \\
\hline Odeda & Biannual & $39442(3278,121247)$ & $316882(32924,528789)$ & $13508(1120,41538)$ & $108502(11211,181054)$ \\
\hline Odogbolu & Annual & $21905(1713,82002)$ & $163692(2221,455374)$ & $7888(618,29504)$ & $58971(811,163260)$ \\
\hline OgunWaterside & Annual & $19173(951,69839)$ & $134592(2821,303131)$ & $7182(356,26161)$ & $50417(1058,113550)$ \\
\hline Remo-North & Biannual & $17235(1839,51901)$ & $146251(16767,248217)$ & $6242(667,18797)$ & $52931(6081,89937)$ \\
\hline Shagamu & Annual & $57167(4014,206168)$ & $384169(5089,1044285)$ & $19111(1348,68879)$ & $128492(1712,349374)$ \\
\hline Yewa North & Biannual & $60549(5210,177513)$ & $458509(63126,762141)$ & $21709(1868,63641)$ & $164417(22648,273179)$ \\
\hline Yewa South & Biannual & $73838(8555,197955)$ & $543215(127154,815251)$ & $25343(2936,67936)$ & $186407(43634,279757)$ \\
\hline Total & & $1099461(103402,3420260)$ & $7866374(861403,15497817)$ & $375374(35339,1166152)$ & $2685618(294614,5281949)$ \\
\hline
\end{tabular}

\footnotetext{
* Total population comprises of preschool-aged children, school-aged children and adults
} 


\section{Discussion}

In this study, we utilized soil-transmitted helminth infection data from a state-wide cross-

433 sectional survey to produce model-based estimates of infection risk, number of people infected,

434 rounds of MDA and annual drug requirements for preventive chemotherapy. Empirical

435 prevalence estimates for each of the three STH were below 20\%, with Ascaris lumbricoides been

436 the most predominant species (13.6\%), followed by hookworm (4.6\%) and Trichuris trichiura

437 (1.7\%) [19]. However, based on our model predictions, prevalence ranged from $5.0 \%$ to $23.8 \%$

438 for Ascaris lumbricoides, from $2.0 \%$ to $14.5 \%$ for hookworms, and from $0.1 \%$ to $5.7 \%$ for

439 Trichuris trichiura across the IUs. However, location-specific predictions shows that overall

$440 \mathrm{STH}$ and Ascaris infections were as high as $53 \%$ and $34 \%$ respectively, and greatest around the

441 border of Republic of Benin in the west. Also, heavy risk approaching thresholds level 442 necessitating preventive chemotherapy were observed in the central and western region. The risk

443 of hookworms, also exhibit a similar pattern, however the predicted prevalence was further 444 reduced below PC threshold levels. Majority of the LGAs were at very low risk of Trichuris 445 infection. The spatial patterns observed in this study is in-line with the findings of [24] for the 446 three STH species, except for Ascaris lumbricoides where additional risk was reported in the 447 eastern part of the state. This observation might be explained by the differences in composition 448 of the study population (total population versus SAC only) and sampling point (communities 449 versus school) in this present study [19, 24]

451 Furthermore, our results indicate the influence of some environmental covariates on transmission 452 of soil transmitted helminth infections. For example, soil $\mathrm{pH}$ was negatively associated with 453 Ascaris, suggesting that as $\mathrm{pH}$ of the soil increases, the survivability of Ascaris egg reduces. The 
454 effect of elevated $\mathrm{pH}$ on inactivation of Ascaris eggs have been previously reported [41].

455 Similarly, soil moisture was negatively associated with the risk of hookworm infection. This

456 finding corroborates the observation of [42]. Temperature and moisture are determining factors

457 in the development of helminth eggs [43], with rainfall playing a major role in the restoration of 458 the latter [44]. However, there are presumptions that heavy rainfalls might wash out soil 459 transmitted helminth eggs from the soil $[23,43,45]$. This might explain the negative relationship 460 between soil moisture and hookworm infections. Also, elevation was negatively associated with 461 Trichuris. This supports already established evidence that the risk of Trichuris trichiura is rare or 462 absent as altitude increases [46, 47]. Our findings are also in-line with previous reports from 463 Bolivia [48] and Nigeria [24].

465 STH infections thrives in areas lacking sanitation, potable water source, personal and domestic 466 hygiene $[4,7,9,19]$, hence we expected infections to be associated with socio-economic 467 predictors such as access to improved sanitation and drinking water facilities. However, none of 468 the socioeconomic variables were picked during the geostatistical variable selection process. 469 This finding is similar with those reported in Cambodia [22], India [49], Ethiopia [50] and 470 Australia [51]. Reasons for the no-effect association may not be limited to; (i) probable loss of 471 variability as a result of household data aggregation for community analysis [22], (ii) insufficient 472 coverage of water and sanitation resource facilities [49], (iii) Lack of standard and better water, 473 sanitation and hygiene assessment tool leading to information bias [50] and latrine efficiency in 474 containing excreta [50]. 
476 Prior efforts to model the treatment needs and number of SAC infected in Ogun State, were

477 based on national survey data collected across 555 locations in Nigeria, with less than 20

478 location-specific data in Ogun State [24]. Indeed, these data may not reflect the actual situation

479 of infected SAC and drug requirements for PC in the state [24]. Our study therefore presents, a

480 robust estimate for the state, using real-time survey data collected across 1,027 locations in the

481 State. Based on our estimate, half (10/20) of the IUs in the State requires biannual rounds of 482 MDA, while 40\% (8/20) and 10\% (2/20) requires annual and biennial MDA rounds respectively.

483 We therefore estimated a total of 1.1 million infected persons (comprising preschoolers, school484 aged children and adults), requiring 7.8 million albendazole or mebendazole tablets in Ogun 485 State. More specifically, we estimate that 375,374 SAC were infected and require a total of 2.7 486 million tablets for PC. These estimates are twice as high as the number of tablets reported in [24] 487 for the state.

489 This study has shown the predicted prevalence using a robust geostatistical approach, and as well 490 the spatial pattern of disease spread. The empirical and predicted prevalence for Ascaris 491 infections were above 20\%, hence necessitating annual PC in most regions. However, there were 492 significant reduction in the prevalence and spread of Hookworm and Trichuris infections. This 493 observation reflects the yields of investment made by the WHO, donor agencies, and various 494 governmental and non-governmental health development agencies supporting PC in the country.

496 Our predictive maps and estimated drug requirements are therefore important in planning, 497 targeting and delivery of prioritized interventions. The maps can also be utilized for designing 498 more robust spatial surveys to meet more specialized needs including evaluation of STH control 
499 programs or long-term surveillance. Furthermore, we believe our estimations on the number of

500 preschoolers and adults infected are useful, in the phase of expanding PC to adult population, to

501 sustain accrued gains in morbidity control and interruption of transmission [52].

\section{Conclusion}

504 The work presented here is the first major effort to present model-based estimates of the 505 geographical distribution of soil-transmitted helminth infection risk at more finite scale (i.e., 506 scale smaller than the implementation units) in Ogun State in Nigeria. We used data generated 507 across a community based cross-sectional study focusing on all sub-sets of a population 508 (preschoolers, school-aged children and adults) to; (i) predict disease distributions, (ii) identify 509 associated environmental and socioeconomic risk factors, (ii) estimate number of persons 510 infected, and (iv) estimate annual drug requirements. Our prediction maps provide useful 511 information for identifying priority areas where interventions targeting soil transmitted

512 helminthiasis are most urgently required. In addition, our estimations of drug needs are useful in 513 the process of resource acquisition, planning and delivery of interventions.

\section{List of abbreviations}

517 PC: Preventive Chemotherapy; STH: Soil Transmitted Helminths; WHO: World Health 518 Organization; SAC: School-aged Children; GIS: Geographic Information System; RS: Remote 519 Sensing; IU: Implementation Units; LGAs: Local Government Areas; SAF: Sodium Acetate 520 Acetic Acid Formaldehyde; NDVI: Normalized Difference Vegetation Index; EVI: Enhanced 521 Vegetation Index; LSTD: Land Surface Temperature for Day; LSTN: Land Surface Temperature 522 for Night; MDA: Mass Drug Administration; NLE: Night Light Emission; MODIS/TERRA: 
523 Moderate Resolution Imaging Spectroradiometer; C3S: Corpernicus Climate Change Service;

524 WORLDPOP: World Population Database; LBD: Local Burden of Disease Project; AIC: Akaike

525 Information Criterion; GMRF: Gaussian Markov Random Field; INLA: Integrated Nested

526 Laplace Approximation; SPDE: Stochastic Partial Differential Equation; CI: Confidence

527 Interval; OR: Odd Ratio; BCI: Bayesian Credible Interval

\section{Declarations}

\section{Ethical approval and consent to participate}

532 Ethical clearance for this study (HPRS/381/183) was obtained from the Ethics review committee 533 of Department of Planning, Research and Statistics, Ogun State Ministry of Health, Oke Imosan

534 Abeokuta, Nigeria. Prior to data collection, visitations were made to the LGAs and the selected

535 communities were the objectives and study procedures were explained and permissions for field

536 survey were sought. Written informed consents were obtained from household heads and 537 corresponding occupants of their households. Children below age sixteen, completed assent 538 forms through their parents or guardians.

\section{Consent for publication}

541 Not applicable

\section{$543 \quad$ Availability of data and materials}

544 The datasets for environmental and socio-economic variables are publicly available in the remote 545 sensing data repositories cited within the text. The primary STH infection datasets analyzed for 546 this study have also been previously published and are available at 


\section{Competing interests}

550 The authors declare that they have no competing interest

$552 \quad$ Funding

553 Not Applicable

\section{Authors' contribution}

557 HOM and UFE conceptualized the study. HOM, UFE, GAA, BSB and SB designed the study. 558 HOM, NOA, ABA and OOJ downloaded remotely-sensed environmental and socioeconomic 559 variables. HOM, NOA and OOJ managed the data, OOJ performed all geostatistical analysis.

560 HOM, ABA, OOJ, UFE interpreted the data. HOM prepared the first draft of the manuscript, 561 which was first reviewed by UFE, ABA, OOJ. All authors contributed to the development of the 562 final manuscript and approved its submission.

\section{Acknowledgement}

565 We are grateful to the community leaders and spokespersons that assisted with entry into the 566 study locations. We also appreciate the study participants for their co-operation and participation.

567 Our appreciation also goes to the Ogun State Ministry of Health for their assistance with field 568 approvals and permits. 


\section{References}

1. WHO. Soil-transmitted helminth infections. World Health Organization. 2020. https://www.who.int/news-room/fact-sheets/detail/soil-transmitted-helminth-infections. Accessed 5 April 2021.

2. Bethony J, Brooker S, Macro A, Geiger SM, Loulas A, Diemert D, et al. Soil transmitted helminth infections: ascariasis, trichuriasis and hookworm. Lancet. 2006;367(9521):1521-32.

3. De Silva NR, Brooker S, Hotez PJ, Montresor A, Engels D, Savioli L. Soil transmitted helminth infections: updating the global picture. Trends Parasitol. 2003;19(12):547-551.

4. Mogaji HO, Dedeke GA, Jaiyeola OA, Adeniran AA, Olabinke DO, et al. A preliminary survey of School-based Water, Sanitation, Hygiene (WASH) Resources and soiltransmitted helminthiasis in eight public schools in Odeda LGA, Ogun State, Nigeria. Parasitology Open. 2017;3(16):1-10. https://doi.org/10.1017/pao.2017.18 worms: knowledge, attitudes, and practices in western Côte d'Ivoire with implications for integrated control. PLoS Negl Trop Dis. 2010;4(12):e910. 
6. Belizario Jr VY, Totañes FIG, de Leon WU, Lumampao YF, Ciro RNT. Soil transmitted helminth and other intestinal parasitic infections among school children in indigenous people communities in Davao del Norte, Philippines. Acta Trop. 2011;120 Suppl 1:12-8.

7. Ziegelbauer K, Speich B, Mäusezahl D, Bos R, Keiser J, Utzinger J. Effect of sanitation on soil-transmitted helminth infection: systematic review and meta-analysis. PLoS Med. 2012;9:e1001162.

8. Schmidlin T, Hürlimann E, Silué KD, Yapi RB, Houngbedji CA, Kouadio BA, et al. Effects of hygiene and defecation behavior on helminths and intestinal protozoa infections in Taabo, Côte d'Ivoire. PLoS one. 2013;8: e65722.

9. Strunz EC, Addiss DG, Stocks ME, Ogden S, Utzinger J, Freeman MC. Water, sanitation, hygiene, and soil-transmitted helminth infection: a systematic review and meta-analysis. PLoS Med. 2014;11: e1001620.

10. WHO. Eliminating Soil-Transmitted Helminthiases as a Public Health Problem in Children. Progress Report 2001-2010 and Strategic Plan 2011-2020. World Health Organization, Geneva. 2012. https://apps.who.int/iris/bitstream/handle/10665/44804/9789241503129_eng.pdf. Accessed 5 April 2021. 11. NTSDC. \$812 Million NTD Funding Pledged, World Record Set for Drug Donations \& Other NTD News. Neglected Tropical diseases Support Center. 2017 https://www.ntdsupport.org/news/812-million-ntd-funding-pledged-world-record-set-drug-donationsother-ntd-news. Accessed 5 April 2021. global progress of soil-transmitted helminthiases control in 2020 and World Health 
Organization targets for 2030. PLoS Negl Trop Dis. 2020;14(8):e0008505. doi: 10.1371/journal.pntd.0008505.

626 13. WHO. Schistosomiasis and soil-transmitted helminthiases: number of people treated in 2018. Wkly Epidemiol Rec. World Health Organization. 2019;50:601-12. https://extranet.who.int/iris/restricted/bitstream/handle/10665/330108/WER9450-eng-

$629 \quad$ fre.pdf?ua=1. Accessed 5 April 2021.

14. WHO. 2030 targets for soil-transmitted helminthiases control programmes. Geneva: World Health Organization; 2019. Licence: CC BY-NC-SA $3.0 \quad$ IGO. https://apps.who.int/iris/bitstream/handle/10665/330611/9789240000315-eng.pdf?ua=1. Accessed 5 April 2021.

15. WHO. Ending the neglect to attain the Sustainable Development Goals: A road map for neglected tropical diseases 2021-2030. World Health Organization. 2020. https://www.who.int/neglected_diseases/Ending-the-neglect-to-attain-the-SDGs-NTDRoadmap.pdf?ua=1\#: :text=The\%20road\%20map\%20for\%202021,targets\%20durin g\%20the\%20next\%20decade. Accessed 5 April 2021.

16. Li T, He SY, Zhao H, Zhao GH, Zhu XQ. Major trends in human parasitic diseases in China. Trends Parasitol. 2010;26:264-270. helminth infections and correlated risk factors in preschool and school-aged children in rural southwest China. PLoS One. 2012;7:e45939.

18. Zhou XN, Bergquist R, Tanner M. Elimination of tropical disease through surveillance and response. Infect Dis Poverty. 2013;2:1. 
19. Mogaji HO, Dedeke GA, Bada BS, Bankole S, Adeniji A, Fagbenro MT, et al. Distribution of ascariasis, trichuriasis and hookworm infections in Ogun State, Southwestern

Nigeria.

PLoS

ONE.

2020;15(6):e0233423. https://doi.org/10.1371/journal.pone.0233423

20. Lai YS, Zhou XN, Utzinger J, Vounatsou P. Bayesian geostatistical modelling of soiltransmitted helminth survey data in the People's Republic of China. Parasit Vectors. 2013;6:359.

21. Yapi RB, Chammartin F, Hürliman NE, Houngbedji CA, N'Dri PB, Silué KD, et al. Bayesian risk profiling of soil-transmitted helminth infections and estimates of preventive chemotherapy for school-aged children in Côte d'Ivoire. Parasit Vectors. 2016;9:162. DOI 10.1186/s13071-016-1446-0

22. Karagiannis-Voules DA, Odermatt P, Biedermann P, Khieu V, Schär F, Muth S, et al. Geostatistical modelling of soil-transmitted helminth infection in Cambodia: Do socioeconomic factors improve predictions. Acta Trop. 2014;141:2014-212 transmitted helminth infection in South America: a systematic review and geostatistical meta-analysis. Lancet Infect. Dis. 2013;13:507-518. Bayesian Geostatistical Model-Based Estimates of Soil-Transmitted Helminth Infection in Nigeria, Including Annual Deworming Requirements. PLoS Neglected Tropical Diseases. 2015;9(4):e0003740. doi:10.1371/journal.pntd.0003740 
25. Hotez PJ, Kamath A. Neglected tropical diseases in sub-Saharan Africa: review of their prevalence, distribution and disease burden. PLoS Negl Trop Dis. 2009;3:e412. doi: 10.1371/journal.pntd. 0000412

26. Hotez PJ, Asojo OA, Adesina AM. Nigeria: "Ground Zero" for the high prevalence neglected tropical diseases. PLoS Negl Trop Dis. 2012;6:e1600. doi: 10.1371/journal.pntd.0001600

27. Yaro CA, Kogi E, Luka SA. Spatial Distribution and Modeling of Soil Transmitted Helminthes Infection in Nigeria. AID. 2018;8:82-107.

28. Ekpo UF, Hürlimann E, Schur N, Oluwole AS, Abe EM, Mafe MA, et al. Mapping and prediction of schistosomiasis in Nigeria using compiled survey data and Bayesian geospatial modelling. Geospat Health. 2013;7:355-366.

29. Endriss Y, Elizabeth E, Rohr B, Rohr H, Weiss N. Methods in Parasitology: SAF Method for Stool Specimen. Basel: Swiss Tropical Institute; 2005

30. Deshpande A, Miller-Petrie MK, Lindstedt PA, Baumann MM, Johnson KB, Blacker B, et al. Mapping geographical inequalities in access to drinking water and sanitation facilities in low-income and middle-income countries, 2000-17. Lancet Glob. Population Database: 2017-2018. Accessed 5 January, 2021. and Rainfall Data. https://modis.gsfc.nasa.gov/data/dataprod/. Moderate Resolution Imaging Spectroradiometer (MODIS): 2017-2018. Accessed 5 January, 2021. 
33. SoilGrids250m. Soil pH. https://soilgrids.org/. Soil Grids: 2017-2018. Accessed 5 January, 2021.

34. C3S. Soil Moisture. https://cds.climate.copernicus.eu/cdsapp\#!/dataset/satellite-soilmoisture?tab=overview. Corpernicus Climate Change Service: 2017-2018. Accessed 5 January, 2021.

35. LBD. LMIC drinking water and sanitation geospatial estimates 2000-2017. https://cloud.ihme.washington.edu/s/bkH2X2tFQMejMxy._Local Burden of Disease project: 2000-2017. Accessed 5 January, 2021.

36. Rue H, Martino S, Chopin N. Approximate Bayesian inference for latent Gaussian

37. Moraga P. Geospatial health data: Modeling and visualization with R-INLA and shiny. CRC Press; 2019.

38. Lindgren F, Rue H, Lindström J. An explicit link between Gaussian fields and Gaussian Markov random fields: the stochastic partial differential equation approach. J R Stat Soc Ser A Stat Soc: Series B (Statistical Methodology).2011;73(4):423-498.

39. de Silva N, Hall A. Using the prevalence of individual species of intestinal nematode worms to estimate the combined prevalence of any species. PLoS Negl Trop Dis. 2010;4(4):e655. https://doi.org/10.1371/journal.pntd.0000655

40. WHO. Helminth control in school-age children: a guide for managers of control $\begin{array}{llll}\text { programmes. } & \text { World } & \text { Health } & \text { Organization. }\end{array}$ https://www.who.int/neglected_diseases/resources/9789241548267/en/._Accessed 15 April 2021 
713 41. Senecal, J, Nordin A, Vinnerås B. Fate of Ascaris at various pH, temperature and

714 moisture levels. J Water Health. 2020;18(3):375-382.

715 https://doi.org/10.2166/wh.2020.264

716 42. Chammartin F, Guimarães LH, Scholte RGC, Bavia ME, Utzinger J, Vounatsou P.

717 Spatio-temporal distribution of soil-transmitted helminth infections in Brazil. Parasit

718 Vectors. 2014;7(440: https://doi.org/10.1186/1756-3305-7-440

719 43. Brown HW. Studies on the rate of development and viability of the eggs of Ascaris

720 lumbricoides and Trichuris trichiura under field conditions. J Parasitol. 1927;14:1-15.

721 44. Shreve F. Rainfall as a determinant of soil moisture. Plant World. 1914;17(1):9-26

722 45. Gunawardena GS, Karunaweera ND, Ismail MM. Wet-days: are they better indicators of 723 Ascaris infection levels?. J Helminthol. 2004;78:305-310.

724 46. Bundy DAP, Cooper ES. Trichuris and trichuriasis in humans. Adv Parasitol. 1989;28: $725 \quad 107-173$.

726 47. Nolf LO. Experimental studies on certain factors influencing the development and 727 viability of the ova of human Trichuris as compared with those of the human Ascaris. 728 Am. J. Hyg. 1932;16:288-322.

729 48. Chammartin F, Scholte RGC, Malone JB, Bavia ME, Nieto P, Utzinger J, et al. 730 Modelling the geographical distribution of soil-transmitted helminth infections in Bolivia. 731 Parasit Vectors. 2013;6:152. https://doi.org/10.1186/1756-3305-6-152

732 49. Clasen T, Boisson S, Routray P, Torondel B, Bell M, Cumming O, et al. Effectiveness of 733 a rural sanitation programme on diarrhoea, soil-transmitted helminth infection, and child 734 malnutrition in Odisha, India: a cluster-randomised trial. Lancet Glob. 2014;2:e645-53. 
735 50. Oswald WE, Stewart AEP, Kramer, MR, Endeshaw T, Zerihun M, Melak B, et al. 736 Association of community sanitation usage with soil-transmitted helminth infections 737 among school-aged children in Amhara Region, Ethiopia. Parasit and Vectors. $2017 ; 10: 91$

739 51. Campbell SJ, Nery SV, Wardell R, D'Este CA, Gray DJ, McCarthy JS, et al. Water, 740 Sanitation and Hygiene (WASH) and environmental risk factors for soil-transmitted 741 helminth intensity of infection in Timor-Leste, using real time PCR. PLoS Negl Trop. 2017;11(3):e0005393. https://doi.org/10.1371/journal.pntd.0005393

743 52. Karagiannis-Voules DA, Biedermann P, Ekpo UF, Garba A, Langer E, Mathieu E, et al. 744 Spatial and temporal distribution of soil-transmitted helminth infection in sub-Saharan 745 Africa: a systematic review and geostatistical meta-analysis. Lancet Infect Dis. 2015;15:74-84 doi:10.1016/S1473-3099(14)71004-7 
Figures

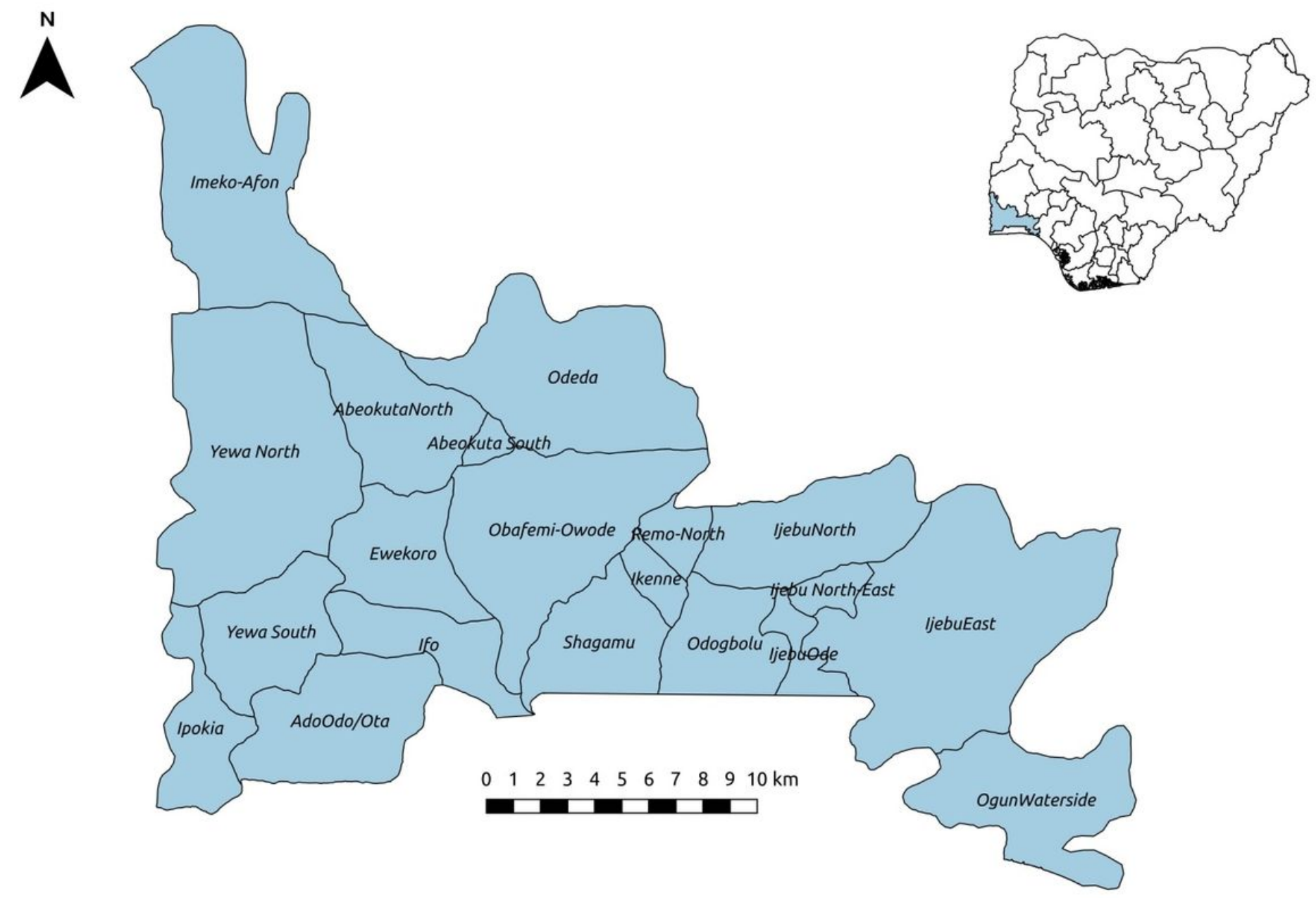

\section{Figure 1}

Map of the Ogun State showing the 20 implementation units (IUs) with Nigeria as inset 


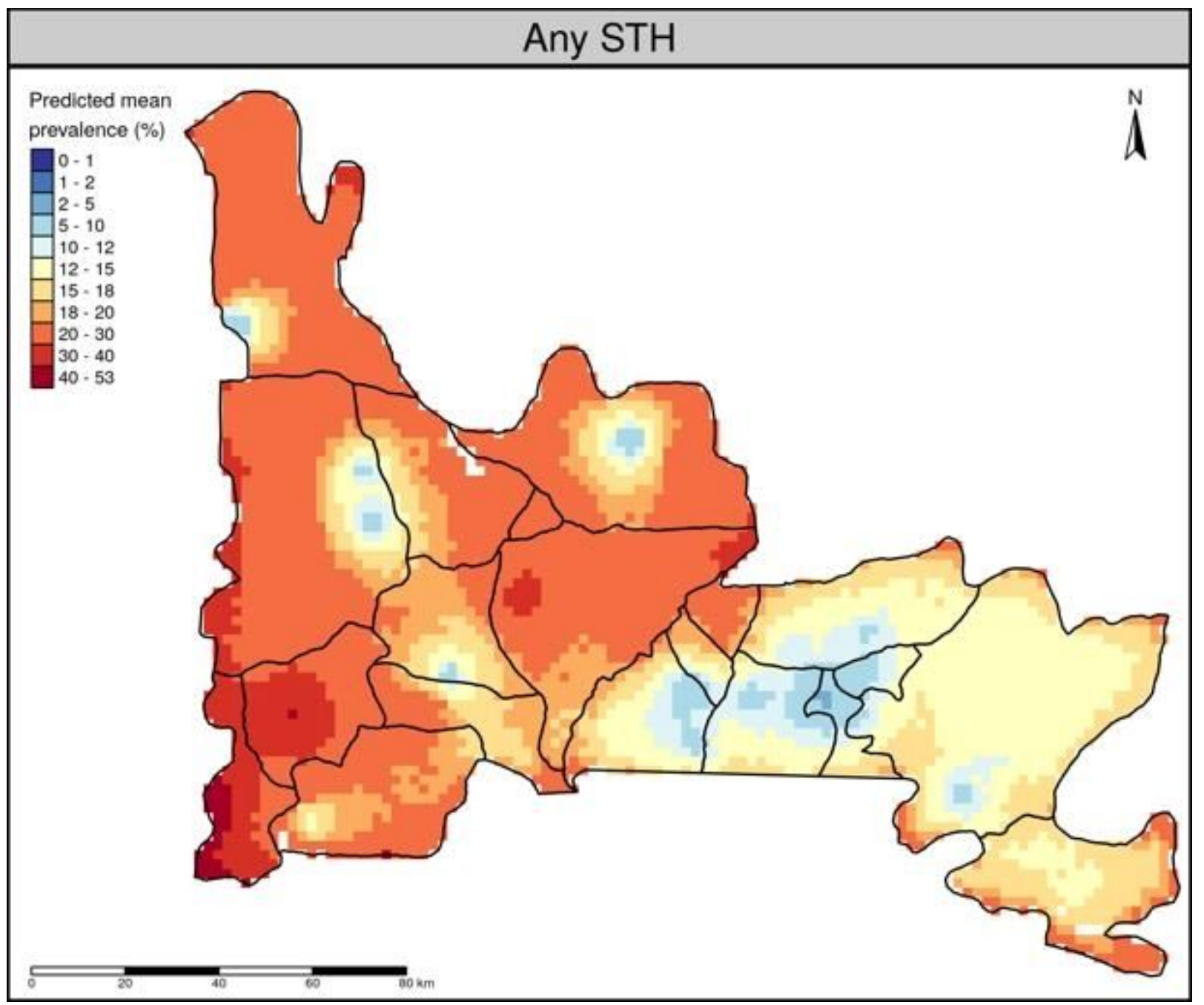

Figure 2

Map showing the predicted risk of Any soil transmitted helminth infections in Ogun State 


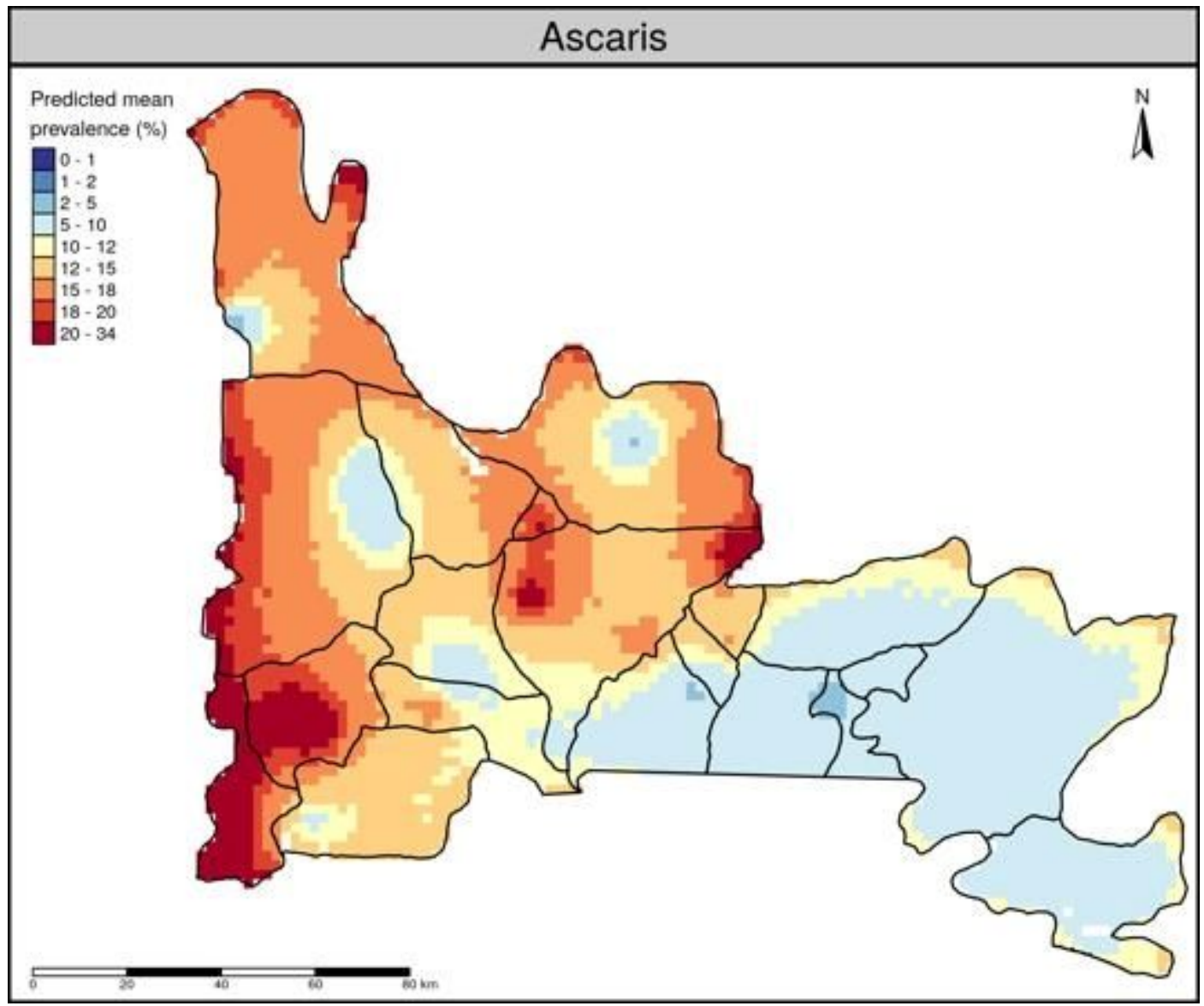

Figure 3

Map showing the predicted risk of Ascaris lumbricoides infections in Ogun State 


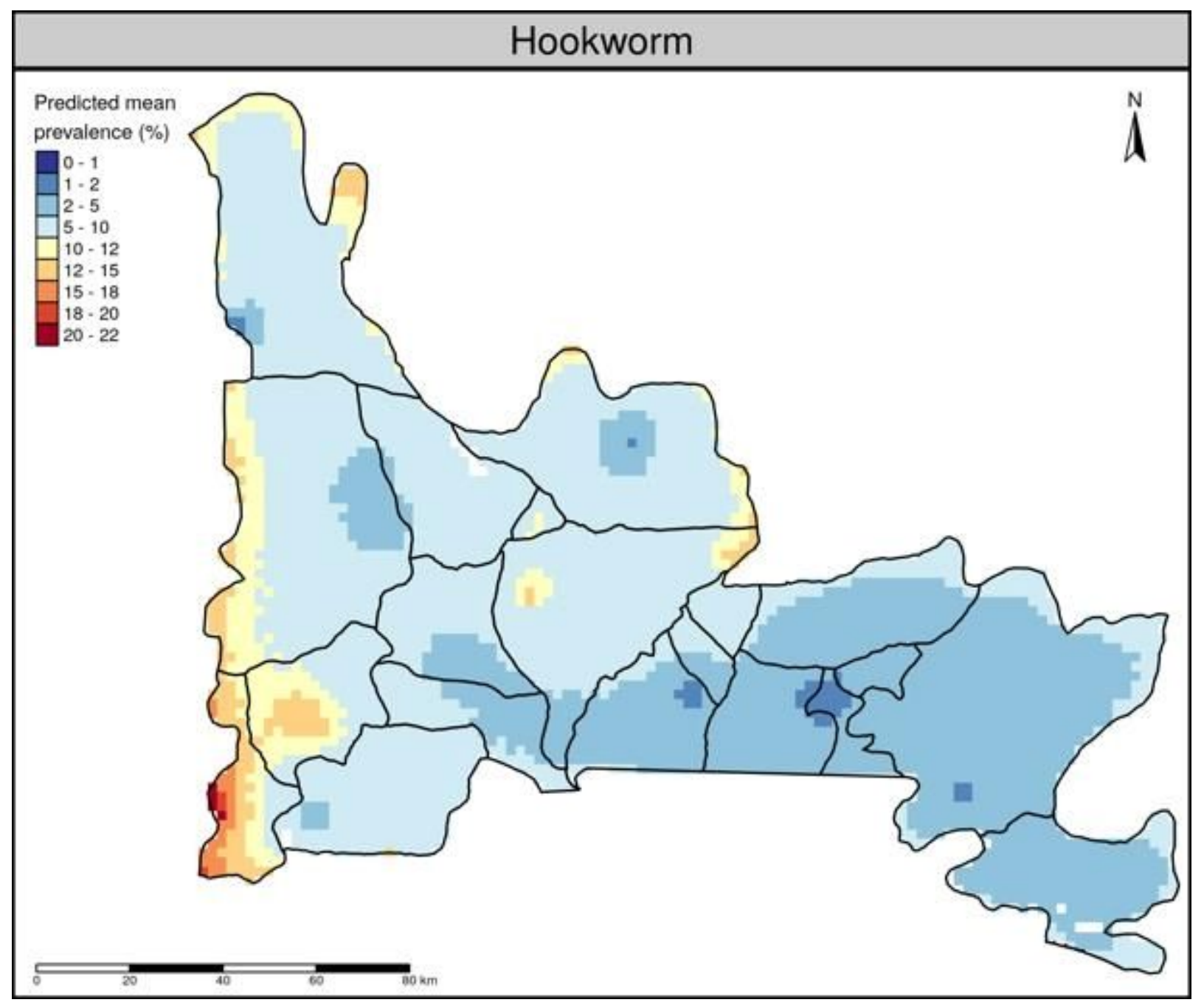

Figure 4

Map showing the predicted risk of Hookworm infections in Ogun State 


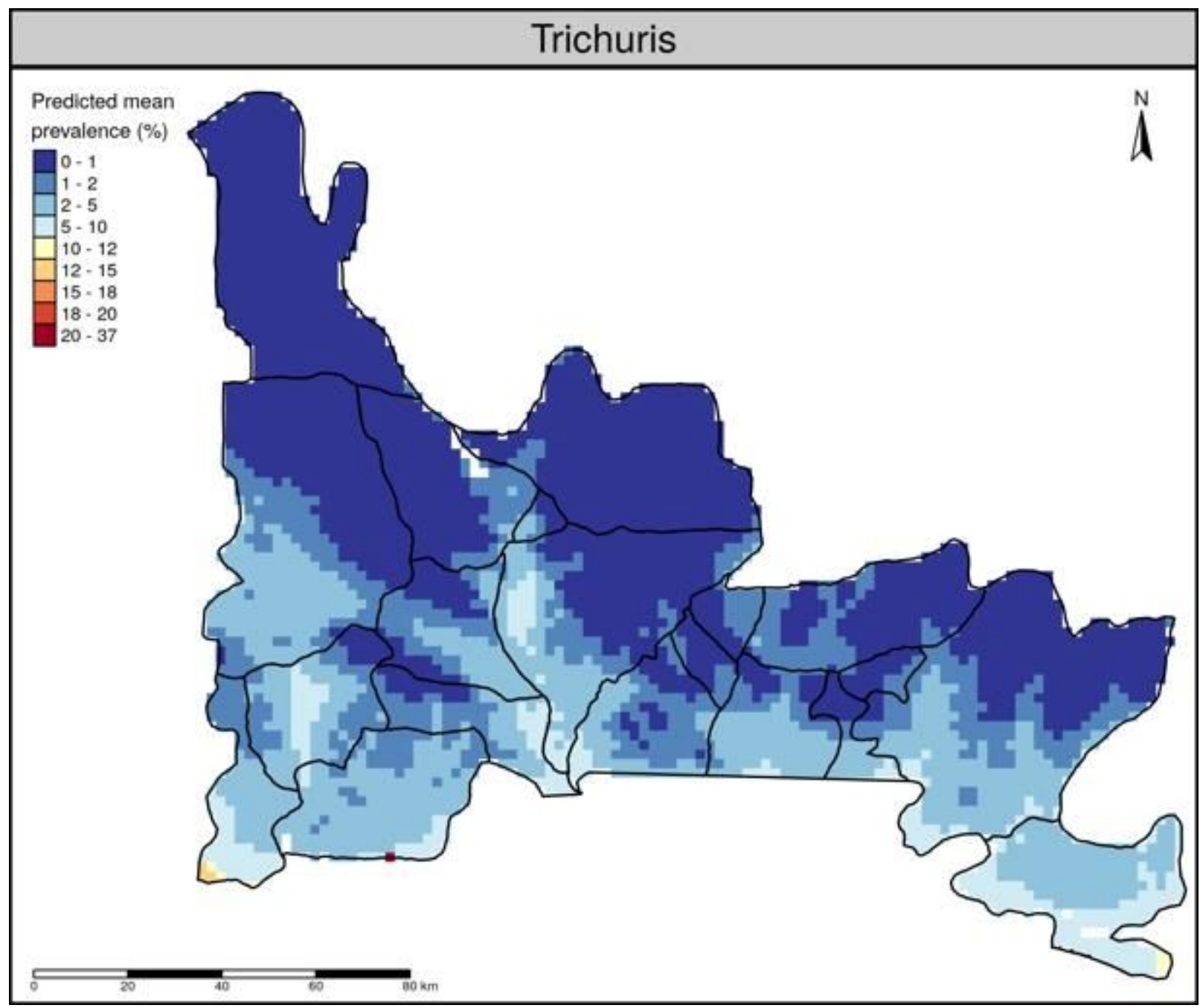

Figure 5

Map showing the predicted risk of Trichuris trichiura infections in Ogun State

\section{Supplementary Files}

This is a list of supplementary files associated with this preprint. Click to download.

- Graphicalabstract.jpg 